\title{
Complications Following Endobutton for Anterior Cruciate Ligament Reconstruction
}

\author{
Rafik Yassa*, John Adam and Marya Qulta \\ Department of Trauma and Orthopaedics, UK \\ *Corresponding author: Rafik Yassa, Department of Trauma and Orthopaedics, Manchester M1 3BN, UK
}

Submission: 眥 May 05, 2018; Published: 㘹 May 30, 2018

\section{Opinion}

Anterior cruciate ligament reconstruction proved to be the commonest sports injury worldwide. The annual incidence is increasing and is commoner among the professional athlete than the armature ones [1]. Surgical reconstruction of the torn anterior cruciate ligament is performed to restore knee stability and to decrease the adverse consequences of knee instability namely injury to other intraarticular structures [2]. There are a number of options for the femoral fixation of the hamstring graft including interference screw, endobutton and femoral cross-pin. The Endobutton (EB) suture loop and metal plate is commonly used and is relatively cheap. However, there is a number of recognized complications.

Firstly, breaking of the guide wire has been noted. One cause for this is that the guide wire is not inserted in a straight line, causing too much tension on it. Also, if the guide wire has been passed on multiple attempts and has become deformed, this may cause a stress riser in the material. Similarly, we postulate that if the drill is not inserted in a straight line over the guide wire, then this may also cause increased tension leading to it breaking. Another reason for breaking is faulty equipment.

Secondly, the endobutton may not be seated fully onto the outer cortex which can be due to muscle entrapment. This is because one cannot ensure the endobutton has been pulled too far away from the outer cortex before seating it. One must ensure that the endobutton is fully seated, by feeling for feedback as it is positioned, as well as testing the graft integrity and checking the marking on it. If there any concerns when seating the endobutton, we would advise intraoperative radiography to confirm its position.

Thirdly, there are reported cases where the endobutton has become stuck in the tunnel. This is potentially either because it was deployed horizontally before reaching the outer cortex, or that the outer cortex was over drilled. For cases where the EB has fallen into the joint, the causes would be similar to those that caused it to be stuck in the tunnel, except that it has migrated even further.
We would recommend scoping the tunnel intraoperatively before graft insertion to check that there is no debris that may prevent the desired seating of the graft or potentially flipping the endobutton causing it to get stuck before it reaches the outer cortex.

Another complication associated with use of endobuttons is intraoperative fracture. Muneta et al. [3] reported two cases of posterolateral femoral drill hole breakage. Therefore, one should avoid drilling the tunnel too far posterior. One can also check that a tunnel has not blown-out via direct visualization of tunnel with the scope before graft insertion. If a blow-out has occurred, one can use a larger, extended endobutton.

With regards to post operative complications, these include late migration, local irritation around the endobutton and fracture. Mae et al. [4] reported on whether tissue interposition had an effect on migration of endobuttons and also whether endobutton migration had an effect on clinical outcomes. They found that endobuttons with tissue interposition migrated significantly more frequently than those without tissue interposition. However, neither tissue interposition nor migration of the endobutton affected the clinical outcomes. Uchida et al. [5] noted that endobuttons which were seated distally and posterior, particularly in the area posterior to the lateral supracondylar line, migrated more frequently with no detectable adverse clinical outcome. Taketomi et al. [6] reported two cases of iliotibial band irritation caused by endobuttons. Potential causes for this include mechanical irritation and foreign body reaction.

The presence of an endobutton is also a potential stress riser in the face of trauma. There are reports of distal femur fracture following EB femoral fixation $[7,8]$. There are other factors that may be contributing to risk of fracture. A larger femoral tunnel leaves a larger bone defect through which a fracture can occur. Another factor that may have an influence is the size of the endobutton; the smaller it is, the great the force applied per unit area, for a given graft tension. Hence using a larger endobutton has a theoretical smaller risk of fracture. 


\section{Conclusion}

It is important to be aware of endobuttons' complication during ACL reconstruction in order to prevent them from occurring where possible. Patients should be aware of these complications when being consented for this procedure.

\section{References}

1. Moses B, Orchard J, Orchard J (2012) Systematic review: annual incidence of ACL injury and surgery in various populations. Res Sports Med 20(3-4): 157-179.

2. Zehir S, Zehir R (2014) Suspensory fixation versus novel transverse crosspin for femoral fixation in anterior cruciate ligament reconstruction. Arch Orthop Trauma Surg 134(11): 1579-1585.

3. Muneta T, Sekiya I, Yagishita K, Ogiuchi T, Yamamoto H, et al. (1999) Two-bundle reconstruction of the anterior cruciate ligament using semitendinosus tendon with endobuttons: operative technique and preliminary results. Arthroscopy 15(6): 618-624.
4. Mae T, Kuroda S, Matsumoto N, Yoneda M, Nakata K, et al. (2011) Migration of endobutton after anatomic double-bundle anterior cruciate ligament reconstruction. Arthroscopy 27(11): 1528-1535.

5. Uchida R, Mae T, Matsumoto N, Kuroda S, Toritsuka Y, et al. (2014) The effect of cortical button location on its post-operative migration in anatomical double-bundle anterior cruciate ligament reconstruction. Knee Surg Sports Traumatol Arthrosc 22(5): 1047-1054.

6. Taketomi S, Inui H, Hirota J, Nakamura K, Sanada T, et al. (2013) Iliotibial band irritation caused by the endoButton after anatomic double-bundle anterior cruciate ligament reconstruction: Report of two cases. Knee 20(4): 291-294.

7. Sheps DM, Reed JG, Hildebrand KA, Hiemstra LA (2006) Supracondylar femur fracture after endoscopic anterior cruciate reconstruction using an EndoButton. Clin J Sport Med 16(5): 428-429.

8. Bradshaw AR, Morris A (2014) Fracture of the lateral femoral condyle through an anterior cruciate ligament graft tunnel. A case report. Current Orthopaedic Practice 25(2): 191-192.
Creative Commons Attribution 4.0 International License

For possible submissions Click Here

\section{Submit Article}

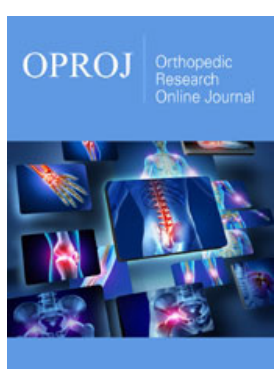

Orthopedic Research Online Journal

\section{Benefits of Publishing with us}

- High-level peer review and editorial services

- Freely accessible online immediately upon publication

- Authors retain the copyright to their work

- Licensing it under a Creative Commons license

- Visibility through different online platforms 